\title{
PENGARUH BUERGER ALLEN EXERCISE TERHADAP SIRKULASI EKTREMITAS BAWAH PADA PASIEN LUKA KAKI DIABETIK
}

\author{
Jannaim $^{1 *}$, Ridha Dharmajaya ${ }^{2}$, Asrizal $^{3}$ \\ 1. Master's Program Faculty of Nursing Universitas Sumatera Utara, Medan 20222, Indonesia \\ 2. Faculty of Nursing Universitas Sumatera Utara, Medan 20222, Indonesia \\ 3. Faculty of Medicine Universitas Sumatera Utara, Medan 20222, Indonesia \\ *E-mail: siak.laksamana@yahoo.co.id
}

\begin{abstract}
Abstrak
Luka kaki diabetes (LKD) merupakan komplikasi penyakit diabetes yang disebabkan oleh gangguan sirkulasi darah vena dan arteri. Buerger allen exercise adalah terapi modalitas dengan gerakan postural aktif. Penelitian ini bertujuan untuk menilai pengaruh buerger allen exercise tehadap peningkatan sirkulasi ektremitas bawah pasien LKD. Desain penelitian adalah pre eksperimen pretest dan posttest without control. Teknik pengambilan sampel adalah consecutive sampling sebanyak sampel 43 responden LKD, analisis data menggunakan uji Wilcoxon. Peningkatan sirkulasi di ukur menggunakan Ankle Brachial Index (ABI). Latihan dilakukan sebanyak 2 kali sehari dengan waktu latihan 17 sampai 20 menit, selama 3 minggu. Hasil penelitian menunjukkan perbedaan signifikan antara nilai rata-rata ABI sebelum 0,84 dan sesudah 0,95 intervensi Buerger allen exercise dengan nilai $\mathrm{p}=0,000$. Buerger allen exercise efektif untuk meningkatkan sirkulasi LKD karena perubahan posisi dan gaya gravitasi membantu mengosongkan dan mengisi kolom darah, sedangkan kontraksi muskulus gastrocnemius sebagai muscle pump mengaktivasi pembuluh darah vena dan arteri untuk membuka jalur sirkulasi collateral lokal.
\end{abstract}

Kata Kunci: Luka kaki diabetik, ankle brakial indeks, Buerger allen exercise

\begin{abstract}
The Influence of Buerger Allen Exercise on Lower Extremity Circulation in Patients with Diabetic Foot Ulcer. Diabetic foot ulcer (DFU) is a complication of diabetes caused by impaired venous and arterial blood circulation. Buerger allen exercise is a modality therapy with active postural movement. This study aims to assess the effect of buerger allen exercise on the circulation of lower extremities in DFU patients. The study design was pre experimental pretest and posttest without control. The sampling technique was consecutive sampling and the large sample of 43 DFU patients, analysis data was using Wilcoxon test. Increased circulation is measured using the Ankle Brachial Index (ABI). Exercise done as much as 2 times a day with practice time 17 to 20 minutes, for 3 weeks. The results showed a significant difference between the average value of ABI before 0.84 and after 0.95 intervention of Buerger allen exercise with a value of $p=0.000$. Buerger allen exercise is effective for improving DFU circulation because position changes and gravitational forces help to empty and fill the blood column, and the contraction of the gastrocnemius as a muscle pump activates the venous and arteries and opens the local collateral circulatory pathway.
\end{abstract}

Keyword: Diabetic foot ulcer, brachial ankle index, Buerger allen exercise

\section{Pendahuluan}

Salah satu komplikasi yang berbahaya penyakit diabetes mellitus (DM) adalah luka pada kaki diabetes yang dapat menyebabkan infeksi dan kelainan bentuk kaki sampai dengan amputasi anggota tubuh (Kawasaki, et al., 2013). Bryant dan Nix (2007) menyatakan bahwa luka kaki diabetik disebabkan oleh gangguan pembuluh darah perifer atau oleh bendungan aliran darah vena yang stasis sehingga menurunkan sirkulasi ke ektremitas bawah dan dapat meningkatkan terjadinya udema, LKD juga disebabkan oleh penurunan aliran darah kapiler dan penurunan aliran darah arteri. Menurut Chadwick, Edmonds, dan McCardle (2013), 
penyebab neuropati adalah aliran mikrosirkulasi yang melibatkan arteri, arteriol, kapiler, dan venula post kapiler. Sedangkan RosalesVelderrain, Padilla, Choe, dan Hargens (2013), menyatakan masalah sirkulasi vena dapat mengakibatkan terhambatnya arus balik darah, yaitu pompa otot vena tungkai bawah untuk mengembalikan darah ke jantung (mekanisme pompa otot betis) dalam melawan efek gravitasi. Disfungsi pompa otot merupakan mekanisme terjadinya inkompetensi vena superfisial dan komplikasi terjadinya LKD (Black \& Hawks, 2014).

International Diabetes Federation (IDF) (2015), menyatakan prevalensi DM di dunia tahun 2015 mencapai 7,3 milyar orang dan diprediksi akan meningkat tahun 2040 menjadi 9 milyar orang. IDF menyebutkan Indonesia saat ini berada pada posisi 7 dengan DM di dunia, dengan jumlah sebanyak 10 juta jiwa dan diprediksi akan meningkat ke posisi 6 pada 2040 dengan jumlah 16,2 juta jiwa yang berpotensi akan komplikasi LKD. Sedangkan Cancellierem (2016), meyebutkan epidemiologi dan implikasi LKD terjadi pada setiap 20 detik di dunia. Diabetik neuropati memengaruhi hampir 50\% dan meningkatkan morbiditas LKD, amputasi dan kematian lebih cepat sampai $85 \%$. Saat ini LKD dianggap sebagai sumber morbiditas dan penyebab utama rawat inap pasien DM sekitar $20 \%$ di rumah sakit. Masalah lain yang dapat disebabkan oleh penyakit LKD adalah gangren, infeksi dan amputasi. Tingkat amputasi anggota ektremitas bawah pada pasien DM adalah 15 kali lebih tinggi daripada pasien tanpa diabetes dengan perkiraaan 50\%-70\% (Yazdanpanah, Nasiri, \& Adarvishi, 2015).

Buerger Allen exercise merupakan salah satu variasi gerakan aktif pada area plantar dengan menerapkan gaya gravitasi sehingga setiap tahapan gerakan harus dilakukan dengan teratur (Chang, et al., 2015). Gerakan yang baik dan teratur membantu meningkatan aliran darah arteri dan vena dengan cara pembukaan kapiler (pembuluh darah kecil di otot), gerakan ini meningkatkan vaskularisasi pembuluh darah sehingga meningkatkan penyediaan darah da- lam jaringan (Salindeho, Mulyadi, \& Rottie, 2016). Disisi lain, para terapis mencatat bahwa keefektifan Buerger Allen exercise dengan beberapa dasar fisiologis, dalam penggunaan pada pasien DM dengan Skin Perfusion Pressures (SPP), Peripheral Arterial Disease (PAD), neuropati dan aterosklerosis. Melalui latihan ini dengan perubahan-perubahan posisi dan kontraksi otot, latihan postural dapat menjamin meningkatkan sirkulasi pembuluh darah vena serta sirkulasi perifer ke ektremitas, sehingga meningkatkan kebutuhan nutrisi ke jaringan dan suplai ke area plantar kaki (Hassan \& Mehani, 2012).

Penelitian yang dilakukan oleh (Chang, et al., 2015) menemukan bahwa, untuk menilai efektivitas Buerger Allen exercise terhadap gangguan perfusi perifer dan nyeri ekstremitas bawah pasien DM, maka evaluasi dapat dilakukan pada hari ke enam. Hasil pre-test pada tingkat nyeri dari 4,33 SD 1,88 post-test menjadi 1,30 SD 1,34 dengan nilai statistik $\mathrm{p}=$ $0,001)$, dan nilai awal pada tingkat perfusi perifer ekstremitas dari 44,50 SD 4,61 nilai akhir menjadi 52,00 SD 3,31dengan $\mathrm{p}=0,001$. Sedangkan penelitian John dan Rathiga (2015), menunjukkan Buerger Allen exercise dengan durasi latihan 10-17 menit 2 kali sehari dilakukan selama 5 hari dapat meningkatkan sirkulasi. Post-test dilakukan pada hari ke 5 menggunakan alat ankle brachial index. Dengan hasil pada kelompok eksperimen terdapat perbedaan yang signifikan antara nilai rerata $\mathrm{ABI}$ awal 0,90 SD 0,05 dan akhir 0,98 SD 0,40, dengan nilai $\mathrm{p}<0,05$.

Hasil penelitian yang dilakukan Chang, et al. (2016), dengan menggunakan alat ukur Transcutaneous Oxygen Monitoring (TCOM/TcPO2) untuk menilai skin perfusion pressures sebelum buerger allen exercise pada pasien yang mengalami iskemia sedang pada ektremitas bawah nilai rerata adalah $42,2 \mathrm{mmHg}$ dan setelah dilakukan intervensi nilai reratanya 64,4 mmHg $\mathrm{p}=0,001$, sedangkan pada pasien yang mengalami iskemia berat nilai rerata sebelum intervensi $22,1 \mathrm{mmHg}$ dan setelah intervensi 
nilai reratanya $37,3 \mathrm{mmHg}(\mathrm{p}=0,043)$. Sedangkan penelitian yang dilakukan oleh Lamkang, Aruna, dan Gowri (2017), hasil dari penelitian pada pasien LKD nilai awal ankle brachial index dengan Buerger Allen exercise pada ekstremits kelompok eksperimen 0,68 SD 0,14 dan nilai rata-rata akhir 0,84 SD 0,11 dengan $\mathrm{p}=$ 0,001 . Sedangkan pada kelompok kontrol nilai awal perfusi ekstremitas bawah sebesar 0,68 SD 0,12 dan nilai rerata akhir 0,68 SD 0,13 dengan $\mathrm{p}=0,096$. Artinya Buerger Allen exercise efektif untuk pengelolaan peripheral arterial disease pada ekstremitas bawah pasien LKD.

Adapun keuntungan dari pemberian intervensi Buerger Allen exercise dalam meningkatkan sirkulasi pada pasien LKD yaitu, mudah, efektif dan ekonomis dapat dilakukan semua pasien dan tidak memiliki efek samping (Vijayabarathi \& Hemavathy, 2014). Berdasarkan uraian tersebut maka peneliti tertarik melakukan penelitian untuk melihat pengaruh Buerger Allen exercise terhadap sirkulasi ektremitas bawah pada pasien LKD.

\section{Metode}

Penelitian ini menggunakan metode kuantitatif dengan desain pre experiment pre dan post tanpa kontrol, yaitu pemberian intervensi pada satu kelompok perlakuan tanpa adanya kelompok pembanding (Dharma, 2015). Penentuan jumlah sampel dalam penelitian ini dengan menggunakan power analisis. Jumlah sampel yang didapatkan dari power 0,8 , effect size 0,5 , dan $\alpha=0,05$ adalah 43 responden. Sampel dalam penelitian yaitu pasien yang menjalani perawatan modern dresing pada luka kaki diabetik di Klinik A Wound Care Medan berjumlah 43 responden LKD. Teknik pengambilan sampel yang digunakan dalam penelitian ini yaitu consecutive sampling. Consecutive sampling merupakan teknik pengambilan sampel dengan cara memilih semua individu yang ditemui dan memenuhi kriteria sampai jumlah sampel yang diinginkan terpenuhi (Dharma, 2015).
Kriteria inklusi penelitian ini yaitu: 1) pasien yang di diagnosa medis menderita LKD mengkonsumsi obat oral gula darah; 2) berusia antara 21-65 tahun; 3) pasien menderita LKD dalam proses perawatan dengan teknik modern dresing; 4) dapat berkomunikasi dengan baik; 5) pasien LKD dengan ulkus arteri dan ulkus vena; 6) pasien yang memiliki skor ABI kurang dari $0,9 \mathrm{mmHg}$.

Sebelum melakukan penelitian, peneliti terlebih dahulu membuat surat izin penelitian dan surat persetujuan etika penelitian dari Komisi Etik Penelitian Kesehatan Fakultas Keperawatan Universitas Sumatera Utara yang ditujukan ke Klinik A Wound Care Medan. Setelah memperoleh surat izin penelitian tersebut maka peneliti melakukan penelitian.

Penelitian ini membedakan nilai ankle brachial index pada ektremitas bawah pada pasien LKD sebelum dan sesudah intervensi pada satu kelompok responden, peneliti mengidentifikasi responden berdasarkan kriteria yang telah dibuat sebelumnya. Kemudian peneliti menjelaskan tata cara proses penelitian, yaitu pertemuan pertama semua sampel dilakukan pengisian kuesioner data demografi responden, melakukan pemeriksaan nilai KGDS, nilai ABI dan melakukan perawatan modern serta mengajarkan teknik Buerger Allen exercise selama 17-23 menit. Latihan dilakukan dua kali sehari dengan rentang jarak per enam jam selama tiga minggu, adapun prosedurnya ada tiga tahap yaitu: 1) ekstremitas bawah atau kaki diangkat pada posisi $45-90^{\circ}$ dengan kaki disanggah oleh bantal, selanjutnya kaki melakukan gerakkan fleksi dan ekstensi selama 2-3 menit atau sampai kulit terlihat menjadi pucat; 2) Pasien duduk dalam posisi santai dengan posisi kaki tungkai kaki digantungkan di bawah tempat tidur atau kursi, selanjutnya kaki pasien melakukan gerakan fleksi dan ekstensi, dan berikutnya melakukan gerakan pronasi dan supinasi atau gerakan kaki ke dalam dan keluar, gerakan ini dilakukan selama 5-10 menit sampai kulit terlihat kemerahan kembali; 3) pasien berbaring ditempat tidur dengan tenang selama 
10 menit dengan kedua kaki pasien beristirahat serta diselimuti kain selama beberapa menit. Alat ukur yang digunakan dalam penelitian ini untuk pengambilan data adalah kuesioner data demografi dan alat ukur Vascular Doppler merek Bistos HI-dop Model BT-200 dan GlocoD007 serta hasilnya dicatat dalam lembar pencatatan hasil pengukuran. Dalam melakukan penelitian ini, peneliti memperhatikan prinsipprinsip dasar etik penelitian dan pertimbangan etik terkait penelitian yang dilakukan yang meliputi beneficence, respect for human dignity dan justice.

Pengolahan data diproses dengan menggunakan bantuan sistem program komputer. Hasil penelitian dianalisis dengan mengunakan analisis univariat dan bivariat. Analisis univariat dilakukan pada data karakteristik responden (Jenis kelamin, umur, lama menderita luka kaki diabetik, mengkonsumsi obat gula darah, kadar gula darah sewaktu dan nilai ankle brachial index), sedangkan analisis bivariat dilakukan pada hasil pengukuran nilai sirkulasi ankle brachial index sebelum dan sesudah pemberian intervensi menggunakan uji Wilcoxon signed ranks test.

\section{Hasil}

Karakteristik Responden. Hasil penelitian menunjukkan sebagian besar responden yang mengalami gangguan sirklulasi ulkus vena dan ulkus arteri yang berjenis kelamin laki-laki sebanyak 25 orang $(58,1 \%)$, dan responden berusia 56-65 tahun sebanyak 27 orang $(62,8 \%)$. Sedangkan responden dengan lama menderita LKD 1-5 tahun sebanyak 34 orang $(79,1 \%)$, dan responden yang mengkonsumsi obat oral gula darah sebanyak 38 orang $(88,4 \%)$.

Distribusi Frekuensi Sirkulasi ABI. Berdasarkan Tabel 1 dapat dilihat bahwa pada pertemuan pada pertama sebelum intervensi nilai ABI responden $(81,4 \%)$ pada kategori gangguan ulkus vena $(0,8-0,9$ mmhg) sebanyak 35 orang, dan sesudah intervensi $(62,8 \%)$ mengalami penurunan menjadi 27 orang. Nilai responden sebelum intervensi $(18,6 \%)$ pada kategori ABI gangguan ulkus arteri $(0,5-0,7$ $\mathrm{mmHg}$ ) sebanyak 8 orang, sesudah intervensi mengalami penurunan menjadi $(0,0 \%)$. Sedangkan nilai $\mathrm{ABI}$ responden sebelum intervensi pada kategori vena normal sebanyak $(0,0 \%)$, sesudah intervensi mengalami peningkatan menjadi $(37,2 \%)$ sebanyak 16 orang.

Rata-Rata Nilai Sirkulasi. Berdasarkan Tabel 2 dapat dilihat bahwa nilai rerata sirkulasi ABI di ektremitas bawah pasien LKD sebelum intervensi 0,84 , median 0,83 , minimum 0,73 dan maximum 1,09 . Sedangkan nilai rerata sirkulasi ABI di ektremitas bawah pasien LKD sesudah intervensi 0,95 , median 0,92 , minimal 0,75 , maksimal 1,18 , dengan nilai $\mathrm{p}=0,000$ yang artinya ada pengaruh yang signifikan.

Tabel 1. Distribusi Frekuensi dan Persentase ABI Penderita LKD

\begin{tabular}{ccccc}
\hline & \multicolumn{4}{c}{ Buerger Allen Exercise } \\
\cline { 2 - 5 } ABI & & Sebelum & Sesudah \\
\cline { 2 - 5 } & f & $\%$ & F & \% \\
\hline Normal & & & 16 & 37,2 \\
$(0,1-1,2 \mathrm{mmHg})$ & 0 & 0,0 & & \\
$\begin{array}{c}\text { Gangguan ulkus vena } \\
(0,8-0,9 \mathrm{mmHg}) \\
\text { Gangguan ulkus arteri } \\
(0,5-0,7 \mathrm{mmHg})\end{array}$ & 35 & 81,4 & 27 & \\
\hline
\end{tabular}


Tabel 2. Pengaruh Buerger Allen Exercise terhadap Sirkulasi LKD Sebelum dan Sesudah Intervensi

\begin{tabular}{lccccc}
\hline \multicolumn{1}{c}{ Buerger Allen Exercise } & $\boldsymbol{N}$ & Mean & Median & Min-Mak & p \\
\hline Sebelum & 43 & 0,84 & 0,83 & $0,73-1,09$ & \\
Sesudah & 43 & 0,95 & 0,92 & $0,75-1,18$ & 0,000 \\
\hline
\end{tabular}

\section{Pembahasan}

\section{Perbedaan Nilai Sirkulasi ABI di Ektremitas Bawah Sebelum Intervensi Buerger Allen} Exercise. Berdasarkan hasil penelitian didapatkan bahwa sebelum intervensi Buerger Allen exercise nilai $\mathrm{ABI}$ responden sebagian besar pada kategori gangguan ulkus vena $(0,8-0,9$ $\mathrm{mmHg})(81,4 \%)$, sedangakan nilai ABI sebelum intervensi pada kategori gangguan ulkus arteri-vena $(0,5-0,8 \mathrm{mmHg})(18,6 \%)$. Rerata nilai ABI sebelum dilakukan buerger allen exercise 0,84 SD 0,89 .

Gangguan sirkulasi ulkus vena dan ulklus arterivena pada pasien LKD dipengaruhi oleh beberapa hal, diantaranya dapat dilihat berdasarkan karakteristik umur responden $(62,8 \%)$ rentang umur lansia awal (56-65 tahun) sebanyak 27 orang. Menurut Thiruvoipati, Kielhorn, dan Armstrong (2015), penderita dengan LKD yang berusia di atas 50 berisiko tinggi mengalami gangguan vaskuler perifer. Sedangkan menurut Dick, et al., (2009) semakin tua usia seseorang akan lebih berisiko menyebabkan gangguan endotel pembuluh darah dan arteriosklerosis.

Berdasarkan jenis kelamin laki-laki yang mengalami gangguan sirkulasi ulkus vena dan ulklus arteri-vena $(58,1 \%)$ sebanyak 25 orang. Pada jenis kelamin laki-laki kadar hormon testosteron dapat mengakibatkan obesitas pada perut dan terjadi resitensi insulin sehingga risiko untuk diabetes tipe 2 (Arnetz, Ekber, \& Alvarsso, 2014). Sedangkan menurut Mclntosh dan Karen (2008), insufiensi sirkulasi arteri ekstremitas bawah kebanyakan dijumpai pada pria dipengaruhi oleh faktor aterosklerois serta penyakit oklusi distal pada geriatri dengan diabetes.
Berdasarkan karakteristik responden berdasar lamanya menderita LKD 1-5 tahun yang mengalami gangguan sirkulasi ulkus vena dan ulklus arteri-vena $(79,1 \%)$ sebanyak 34 orang. Lama menderita LKD dapat memengaruhi dan memperparah terjadinya gangguan sirkulasi darah perifer (Black \& Hawks, 2014) dan responden yang mengkonsumsi obat gula darah $(88,4 \%)$ sebanyak 38 orang. Menurut Lamkang, Aruna, dan Gowri (2017), menjelaskan untuk mengelola penyakit DM dengan gangguan sirkulasi arteri perifer menggunakan manajemen farmakologis sudah terbukti efektif, fokus pada antiplatelet, anti-koagulasi, antibiotik dikombinasi dengan perawatan luka modern dresing. Sedangkan responden yang mengalami gangguan sirkulasi ulkus vena dan ulkus arteri-vena berdasarkan KGDS pada kategori ringan (200$300 \mathrm{mg} / \mathrm{dl}),(76,7 \%)$ sebanyak 33 orang. Vikositas darah memacu terbentuknya mikrotrombus dan penyumbatan mikrovaskular yang berisiko menyebabkan LKD dan memperburuk sirkulasi (Rosenson, Fioretto, \& Dotson, 2011). Kadar glukosa darah yang tinggi menyebabkan viskositas darah meningkat yang mengakibatkan penebalan membran kapiler, dimana sel eritrosit, trombosit, dan leukosit menempel pada lumen pembuluh darah (Suryadi, 2015).

\section{Perbedaan Nilai Sirkulasi ABI di Ektremitas Bawah Sesudah Intervensi Buerger Allen} Exercise. Berdasarkan hasil penelitian, sesudah intervensi buerger allen exercise nilai $\mathrm{ABI}$ responden pada kategori gangguan ulkus vena $(0,8-0,9 \mathrm{mmHg})$ dari $(81,4 \%)$ mengalami penurunan menjadi $62,8 \%$, dan nilai ABI pada kategori gangguan ulkus arteri-vena $(0,5-0,8$ $\mathrm{mmHg}$ ) juga mengalami penurunan dari $18,6 \%$ menjadi $0,0 \%$. Sedangkan nilai ABI kategori normal $(0,9-1,2 \mathrm{mmHg})$ sesudah latihan meng- 
alami peningkatan dari $0,0 \%$ menjadi $37,4 \%$. Dengan rerata nilai ABI pasien LKD sesudah buerger allen exercise 0,95 SD 0,09.

Rosales-Velderrain, et al. (2013) menjelaskan, untuk meningkatnya sirulasi aliran darah mikrovaskuler otot, maka latihan harus dilakukan secara continue dan berulang. Hal ini dikaitkan dengan pelebaran arteri (vasodilatasi), peningkatan permeabilitas kapiler yang memungkinkan terjadinya penyerapan glukosa oleh sel-sel otot (John \& Rathiga, 2015). Sedangkan menurut penelitian Kurniasari, Nuracmah, dan Gayatri (2008) menyatakan bahwa latihan senam kaki merupakan variabel yang paling signifikan berkontribusi terjadinya luka kaki diabetik. Artinya bahwa responden yang melakukan senam kaki tidak sesuai teori mempunyai pelung lebih besar terhadap kejadian luka kaki diabetik, dibandingkan dengan responden yang melakukan senam kaki sesuai dengan teori yang dilakukan secara terus menerus dan berulang.

Buerger Allen exercise terbukti efektif dalam memperbaiki perfusi ekstremitas bawah diantara pasien diabetes mellitus, terdapat peningkatan signifikan perfusi ekstremitas bawah dan pengurangan nyeri pada pasien yang telah diberikan buerger allen exercise pada pasien DM tipe 2. Gravitasi membantu untuk mengosongkan pembuluh darah vena dan mengisi kolom pembuluh darah arteri secara bergantian pada kaki, akhirnya dapat meningkatkan transportasi darah melalui latihan kaki (Bottomley, 2007).

Menurut Jackson (1972), peningkatan perfusi jaringan dari Buerger Allen exercise dikarenakan adanya perubahan postural, dengan memodulasi gravitasi dan menerapkan kontraksi otot dapat meningkatkan perfusi ekstremitas bawah dan membantu untuk proses sirkulasi dan dilatasi pembuluh darah sehingga darah mudah untuk mengalir, buerger allen exercise dilakukan dalam beberapa langkah secara sistematis dengan melakukan fleksi, ekstensi, pronasi, dan supinasi pada jari-jari kaki mampu meningkatkan perfusi perifer.

\section{Pengaruh Buerger Allen Exercise Terhadap Sirkulasi Ekstremitas Bawah pada Pasien} LKD. Berdasarkan hasil analisis uji Wilcoxon didapatkan perbedaan nilai rerata $\mathrm{ABI}$ sebelum intervensi 0,84 dan rerata $\mathrm{ABI}$ sesudah 0,95. Terjadi peningkatan nilai $\mathrm{ABI}$ dengan rerata 0,11 atau termasuk dalam katagori nilai $\mathrm{ABI}$ normal. Hasil penelitian ini mengindentifikasikan bahwa responden mengalami peningkatan sirkulasi dengan nilai $\mathrm{p}=0,000$. Artinya intervensi Buerger Allen exercise mempunyai pengaruh yang bermakna terhadap peningkatan sirkulasi kaki pasien LKD yang mengalami gangguan sirkulasi.

Lamkang, Aruna, dan Gowri (2017) dalam penelitian menjelaskan Buerger Allen exercise pada pasien LKD efektif untuk pengelolaan peripheral arterial disease di ekstremitas. Menurut Aruna dan Thenmozhi (2015), Buerger Allen exercise dapat mencegah terjadinya penyakit arteri perifer dan menurunkan risiko amputasi pasien LKD dan mengembalikan fungsi ekstremitas serta meningkatkan kualitas hidup. Sedangkan menurut John dan Rathiga (2015), Buerger Allen exercise dapat diajarkan pada hari yang sama 2 kali hari dengan interval 6 jam menunjukkan bahwa ada peningkatan yang signifikan pada perfusi ekstremitas bawah. Melakukan elevasi kaki selama 5 menit setiap 2 jam secara berulang dapat meningkatkan sirkulasi dan bermanfaat besar pada insufisiensi vena ektremitas bawah pasien LKD.

Buerger Allen exercise merupakan salah satu variasi gerakan aktif pada area ektremitas bawah dan plantar dengan menerapkan gaya gravitasi sehingga setiap tahapan gerakan harus dilakukan dengan teratur. Latihan ini dilakukan membantu kebutuhan oksigen dan nutrisi ke dalam pembuluh darah arteri dan vena, memperkuat dan memaksimalkan kerja otototot kecil, mencegah terjadinya kelainan bentuk kaki dan memperlancar sirkulasi sehingga membantu proses penyembuhan LKD serta meningkatkan produksi insulin yang dipakai dalam transport glukosa ke sel. Sehingga membantu menurunkan glukosa darah pasien diabe- 
tes (Chang, et al., 2015). Penelitian Kawasaki (2013) Buerger Allen exercise dilakukan pada pasien LKD untuk meningkatkan sirkulasi kolateral pada pasien dengan gangguan peredaran perifer. Efek dari latihan ini disimpulkan bahwa dengan mengulangi posisi terlentang dan posisi duduk secara berkaladan kaki menggantung adalah metode yang efektif meningkatan status hemodinamik kaki pada pasien yang iskemia.

Hasil penelitian ini membuktikan hipotesa penelitian yang menyatakan bahwa pemberian intervensi Buerger Allen exercise dapat meningkatkan sirkulasi ektremitas bawah yang mengalami gangguan sirkulasi ulkus vena dan ulkus arteri-vena pada pasien LKD.

\section{Kesimpulan}

Berdasarkan sirkulasi ekstremitas bawah sebelum Buerger Allen exercise, sebagian besar nilai ABI responden pasien LKD dalam kategori gangguan ulkus vena dan ulkus arteri di pengaruhi oleh karakteristik umur responden di atas 50 tahun, lamanya menderita LKD lebih dari 1 tahun, jenis kelamin laki-laki dan KGDS tidak terkontrol. Nilai sirkulasi ekstremitas bawah sesudah intervensi, mayoritas nilai ABI kategori gangguan vena presentasenya menunujukan penururan, sedangkan pada vena normal presentasenya meningkat. Selain itu, hasil penelitian didapatkan adanya pengaruh signifikan intervensi terhadap peningkatan sirkulasi kaki ekstremitas bawah dengan gangguan ulkus vena dan ulkus arteri pada LKD (BY, TN, PN).

\section{Referensi}

Arnetz, L., Ekberg, N. R., \& Alvarsson, M. (2014). Sex differences in type 2 diabetes: Focus on disease course and outcomes.Diabetes, Metabolic Syndrome and Obesity: Targets and Therapy, 7, 409-420.

Aruna, S. \& Thenmozhi, P. (2015). Effectiveness of allen buerger exercise in preventing peripheral arterial disease among people with type ii diabetes mellitus. International
Journal of Pharma and Bio Sciences, 6 (2), 966-970.

Black, J.M., \& Hawks, J.H. (2014). Keperawatan medikal bedah: Manejemen klinis untuk hasil yang diharapkan (A. Suslia \& P.P. Lestari, Eds.) (8th ed.). Singapore: Elsevier, Pte Ltd.

Bottomley, J.M. (2007). The Insensitive Foot in U.K. Geriatric Rehabilitation Manual. (2nd Ed. Chapter42, Edinburgh). New York: Churchill Living-stone Elsevier.

Bryant, R.A., \& Nix, D.P. (2007). Acute and chronic wounds: Current managemen concepts (3rd Ed.). Philadelphia USA: Mosby Elsevier.

Chadwick, P., Edmonds, M., \& McCardle, J. (2013). Best practice guidelines: Wound management in diabetic foot ulcers. London: Braun.

Cancellierem, P. (2016). Current epidemiology of diabetic foot ulcers. International journal of diabetes, 1 (1), 12-14.

Chang, C.F., Chang C.C., Hwang, S.L., \& Chen, M.Y. (2015). Effects of buerger exercise combined health-promoting program on peripheral neurovasculopathy among community residents at high risk for diabetic foot ulceration. Worldviews on EvidenceBased Nursing, 12 (3), 145-53.

Chang, C.C., Chen, M.Y., Shen, J.H., Lin, Y. Bin, Hsu, W.W., \& Lin, B.S. (2016). A quantitative real-time assessment of buerger exercise on dorsal foot peripheral skin circulation in patients with diabetes foot. Nursing, 95 (46), e5334. doi.10.1097/MD. 0000000000005334.

Dharma, K.K. (2015). Metodelogi penelitian keperawatan: Panduan melaksanakan dan menerapkan hasil penelitian. Jakarta: Trans Info Media.

Dick, F., Diehm, N., Galimanis, A., Husmann, M., Schmidli, J., \& Baumgartner, I. (2009). Surgical or endovascular revascularization in patients with critical limb ischemia: 
influence of diabetes mellitus on clinical outcome. J Vasc Surg, 45, 751-761. doi: 10.1016/j.jvs.2006.12.022.

Hassan, S., \& Mehani, M. (2012). Comparison between two vascular rehabilitation training programs for patients with intermittent claudication as a result of diabetic atherosclerosis. International JournalFaculty of Physical Therapy, Cairo, 17 (1), 7-16.

International Diabetes Federation. (2015). IDF diabetes atlas international diabetes federation (7th Ed.). doi: 10.1289/image. ehp.

Jackson, B.S. (1972). Chronic peripheral arterial disease. American Journal of Nursing, 72, 928-934.

John, J., \& Rathiga, A. (2015). Effectiveness of buerger allen exercise to improve the lower extremity perfusion among patients with type 2 diabetes mellitus. International Journal of Current Research and Academic Review, 3 (4), 252-263. doi: $10.3102 / 0034654310362998$.

Kawasaki, T., Matsuo, K., Masumoto, K., Harada, Y., Chuman, T., Uemura, T., \& Murata, T. (2013). The effect of different positions on lower limbs skin perfusion pressure. Indian Journal of Plastic Surgery, 46 (3), 508. doi: 10.4103/0970-0358.121995.

Lamkang, T.S., Aruna, S., \& Gowri, M. (2017). Effectiveness of buerger allen exercise on level of lower extremity perfusion among patient with type 2 diabetes mellitus. International Journal of Development Research Saveetha Medical, 7 (8), 14723 14726.

Mclntosh, C., \& Karen, O. (2008). Lower extremity wounds: A problem-based learning approach. England: John Wiley \& Sons Ltd. doi.10.1002/9780470697870.

Rosales-Velderrain, A., Padilla, M., Choe, C.H., \& Hargens, A.R. (2013). Increased microvascular flow and foot sensation with mild continuous external compression. Physiological reports, 1 (7), e00157.
Rosenson, R.S., Fioretto, P., \& Dodson, P. M. (2011). Does microvascular disease predict macrovascular events in type 2 diabetes? Atherosclerosis, 218, 13-18. doi: 10.1016/ j.atherosclerosis.2011.06.029.

Salindeho, A., Mulyadi, M., \& Rottie, J., (2016). Pengaruh senam diabetes melitus terhadap kadar gula darah penderita diabetes melitus tipe 2. ejournal Keperawatan, 4 (1), 1-7. https://ejournal.unsrat.ac.id/index.php/jkp/ article/view/10856.

Suryadi, S. (2004). Pengkajian luka dan penanganannya (1st Ed.). Jakarta: CV Sagung Seto.

Kurniasari, S., Nurachmah, E., \& Gayatri, D. (2008). Kejadian kaki diabetik pasien diabetes melitus berdasarkan faktor yang berkontribusi. Jurnal Keperawatan Indonesia, $12 \quad$ (3), 142-147. http://dx.doi.org/10.7454/jki.v12i3.213

Thiruvoipati, T., Kielhorn, C. E., \&Armstrong, E. J. (2015). Peripheral artery disease in patients with diabetes: Epidemiology, mechanisms, and outcomes. World Journalof Diabetes, 6 (7): 961-969. doi: 10.4239/wjd.v6.i7.961.

Vijayabarathi, M., \& Hemavathy, V. (2014). Buerger allen exercise for type 2 diabetes mellitus foot ulcer patients. International Journal of Innovative Research in Science, Engineering and Technology, 3 (12), 17972-17976. doi: 10.15680/ijirset.2014. 0312096.

Yazdanpanah, L., Nasiri, M., \& Adarvishi, S. (2015). Literature review on the management of diabetic foot ulcer. World Journal of Diabetes, 6 (1), 37-53. doi: 10. 4239/wjd.v6.i1.37. 